\title{
Supravalvular Aortic Stenosis Associated with a Deletion Disrupting the Elastin Gene
}

\author{
Amanda K. Ewart, * Weishan Jin, * Donald Atkinson, * Colleen A. Morris," and Mark T. Keating ** \\ *Department of Human Genetics, and ${ }^{\ddagger}$ Cardiology Division, ${ }^{\S}$ Eccles Program in Human Molecular Biology and Genetics, University of \\ Utah, Salt Lake City, Utah 84112; and "Departments of Pediatrics, and Pathology and Laboratory Medicine, University of Nevada \\ School of Medicine, Las Vegas, Nevada 89102
}

\begin{abstract}
Supravalvular aortic stenosis (SVAS) is an inherited vascular disease that can cause heart failure and death. SVAS can be inherited as an autosomal dominant trait or as part of a developmental disorder, Williams syndrome (WS). In recent studies we presented evidence suggesting that a translocation disrupting the elastin gene caused SVAS in one family while deletions involving the entire elastin locus caused WS. In this study, pulsed-field, PCR, and Southern analyses showed that a 100kb deletion of the 3 ' end of the elastin gene cosegregated with the disease in another SVAS family. DNA sequence analysis localized the breakpoint between elastin exons 27 and 28, the same region disrupted by the SVAS-associated translocation. These data indicate that mutations in the elastin gene cause SVAS and suggest that elastin exons 28-36 may encode critical domains for vascular development. (J. Clin. Invest. 1994. 93:1071-1077.) Key words: elastin • supravalvular aortic stenosis • deletion • Williams syndrome • vascular disease
\end{abstract}

\section{Introduction}

Supravalvular aortic stenosis (SVAS) ${ }^{1}$ is an inherited vascular disorder (1). Narrowing of the ascending aorta is a prominent feature of this disease, but other arteries, including the pulmonary arteries, are often affected. If untreated, SVAS may cause myocardial hypertrophy, heart failure, and death. The incidence of SVAS is estimated to be 1 in 25,000 live births (Birth Defects and Genetic Diseases Branch Personnel, Metropolitan Atlanta Congenital Defects Program, Centers for Disease Control, Atlanta, GA, personal communication). The vascular abnormalities typical of SVAS can appear as an isolated case, an autosomal dominant trait, or as part of a second disease, Williams syndrome (WS) (1-3). In addition to vascular disease, WS manifestations include mental retardation, gregarious disposition, premature aging of skin and graying of hair, lax joints

Address correspondence to Dr. Mark Keating, Department of Human Genetics, Suite 2100, Bldg. 533, University of Utah, Salt Lake City, UT 84112.

Received for publication 24 September 1993 and in revised form 10 December 1993.

1. Abbreviations used in this paper: MAGP, microfibril-associated glycoprotein; PFGE, pulsed-field gel electrophoresis; SVAS, supravalvular aortic stenosis; SVPS, supravalvular pulmonic stenosis; WS, Williams syndrome.

J. Clin. Invest.

(C) The American Society for Clinical Investigation, Inc. 0021-9738/94/03/1071/07 \$2.00

Volume 93, March 1994, 1071-1077 early in life followed by joint contractures later in life, diverticulosis of the bladder and colon, hernias, hoarse voice, and dysmorphic facial features (2-4).

In previous experiments we demonstrated linkage between SVAS and the elastin gene in two families (5); recombination between these loci was not observed, making elastin a candidate gene for SVAS. We then showed that a balanced translocation associated with SVAS in one family disrupted the 3' end of the elastin gene $(6,7)$. In WS, by contrast, we discovered submicroscopic deletions involving one entire elastin allele (8). These data lead to the hypothesis that mutations involving part of the elastin gene cause familial SVAS while large deletions involving an entire elastin allele and adjacent loci cause WS. In this study, we describe a second SVAS-associated mutation (a $100-k b$ deletion) that disrupts the elastin gene, supporting the involvement of elastin in this disorder. This deletion, and the previously described translocation, both disrupt the $3^{\prime}$ end of the gene, suggesting that these domains may be important for elastogenesis.

\section{Methods}

Phenotypic evaluation. Informed consent was obtained from all study participants in accordance with standards established by local institutional review boards. To determine if family members and spouses had signs of SVAS or WS, physical examinations and echocardiograms were performed by a medical geneticist as described $(5,9)$.

DNA analysis. Approximately $40 \mathrm{ml}$ of blood was obtained from each family member for genetic analyses. Human genomic DNA was purified from leukocytes and from Epstein-Barr virus-transformed cell lines $(10,11) .5 \mathrm{mg}$ of DNA from each individual was digested with restriction endonucleases (Molecular Biology Resources, Inc., Milwaukee, WI, and New England Biolabs Inc., Beverly, MA) overnight under conditions recommended by the manufacturer supplemented with 4 $\mathrm{mM}$ spermidine. DNA fragments were separated by agarose gel electrophoresis, denatured in $0.4 \mathrm{~N} \mathrm{NaOH}$ for $20 \mathrm{~min}$, and transferred overnight (12) to nylon membranes (Hybond $\mathrm{N}^{+}$; Amersham Corp., Arlington Heights, IL). After transfer, membranes were washed once in $0.1 \times \mathrm{SSC} / 0.1 \%$ SDS before hybridization. Membranes were prehybridized in a hybridization solution containing $10 \%$ polyethylene glycol, $7 \%$ SDS, $1.5 \times \mathrm{SSPE}$, and $250 \mathrm{mg} / \mathrm{ml}$ human placental DNA at $65^{\circ} \mathrm{C}$ for $24 \mathrm{~h}$. Plasmids were denatured and labeled with [ ${ }^{32} \mathrm{P}$ ]dCTP (New England Nuclear, Boston, MA) by random primer synthesis (13) to high specific activity (typically $1-5 \times 10^{9} \mathrm{cpm} / \mathrm{mg}$ DNA). Radiolabeled probe DNAs were hybridized overnight to the Southerns at $65^{\circ} \mathrm{C}$ in fresh hybridization solution. After hybridization, Southerns were washed twice for $15 \mathrm{~min}$, each at room temperature in $0.1 \times \mathrm{SSC}$ and $0.1 \% \mathrm{SDS}$, and then washed for $30 \mathrm{~min}$ at $65^{\circ} \mathrm{C}$. Membranes were exposed to $\mathrm{x}$-ray film (Kodak X-OMAT-AR) backed by intensifying screens (Lightening Plus; DuPont Co., Wilmington, DE) at $-70^{\circ} \mathrm{C}$ overnight.

Pulsed field gel electrophoresis. Agarose plugs containing high molecular weight DNA were made from $10^{8}$ cells from established lymphoblastoid cell lines (14). Cells were resuspended in NET (0.1 M EDTA, 
$20 \mathrm{mM} \mathrm{NaCl}, 10 \mathrm{mM}$ Tris, pH 7.5) and 1\% SeaPlaque (FMC BioProducts, Rockland, ME) agarose in NET. Plugs were incubated overnight with $10 \mathrm{mg}$ proteinase $\mathrm{K}$ (Boehringer Mannheim Biochemicals, Indianapolis, IN), $0.45 \mathrm{M}$ EDTA, $0.9 \mathrm{mM}$ Tris, $\mathrm{pH} 7.5$, and $1 \%$ sarcosyl, and then washed repeatedly over $4 \mathrm{~d}$ in $\mathrm{TE}^{-3}$ followed by $\mathrm{TE}^{-4}$. DNA within the plugs was digested with NotI (New England Biolabs Inc.) according to manufacturer's conditions in $200 \mu$ l total volume with 2.5 $\mathrm{mM}$ spermidine and run on a pulsed field electrophoresis system (Chef-DR II; Bio-Rad Laboratories, Richmond, CA) in 1\% LE agarose (FMC BioProducts) in $0.5 \times$ TBE (22.5 mM trizma base, $22.5 \mathrm{mM}$ boric acid, $0.5 \mathrm{mM}$ EDTA) at $10^{\circ} \mathrm{C}$. Running conditions were initial linear ramp time of $13 \mathrm{~s}$, final linear ramp time of $150 \mathrm{~s}$, run time of $27.3 \mathrm{~h}$, and $200 \mathrm{~V}$. Probing conditions were identical to those described above.

Genomic library construction and screening. Genomic libraries of high molecular weight DNA from affected individual II-2 (Fig. 1) were constructed in pWEX15 (15). Cosmid vector pWEX15 was digested with Xhol and partially filled in with ACTP and dTTP using a cloned Klenow fragment of DNA polymerase I (Molecular Biology Resources, Inc.), leaving 5'-TC-3' at the $5^{\prime}$ end. Genomic DNA was partially digested with $\mathrm{Mbol}$ and fractionated by sucrose-density gradient centrifugation to yield fragments of 35-45 $\mathrm{kb}$. This Mbol 4-bp overhang was filled in with dATP and dGTP using Klenow leaving 5'-GA-3' at the 5' end. Ligation was performed using $1 \mu \mathrm{g}$ of vector and $2 \mu \mathrm{g}$ of genomic DNA in a mixture containing $50 \mathrm{mM}$ Tris- $\mathrm{HCl}, \mathrm{pH} 7.8,10 \mathrm{mM}$ $\mathrm{MgCl}_{2}, 10 \mathrm{mM}$ dithiothreitol, and $1 \mathrm{mM}$ ATP. The reaction mixture was incubated with $2.5 \mathrm{U}$ T4 DNA ligase (Bethesda Research Laboratories, Gaithersburg, MD) at $16^{\circ} \mathrm{C}$ overnight and packaged with in vitro packaging extracts (Gigapack II-XL and Gigapack II Gold; Stratagene, La Jolla, CA). Approximately $2 \times 10^{5}$ primary recombinants were incubated with Escherichia coli strain 490 a and plated at low density according to the manufacturer's instructions. Colony lifts were made with 1.2- $\mu \mathrm{m}$ Biotrans filters (ICN Biomedicals, Inc., Costa Mesa, CA) (16). Prehybridization of library filters was carried out in an aqueous cocktail consisting of $5 \times$ SSPE, $5 \times$ Denhardt's solution, $0.5 \%$ SDS, and $500 \mu \mathrm{g} / \mathrm{ml}$ sheared, denatured herring testes DNA (Sigma Chemical Co., St. Louis, MO) for $4 \mathrm{~h}$. Hybridization was carried out in fresh cocktail after the addition of radiolabeled probe DNA to $>2 \times 10^{6}$ $\mathrm{cpm} / \mathrm{ml}$. Hybridization was performed overnight at $65^{\circ} \mathrm{C}$. Filter washes consisted of one room temperature wash in $2 \times \mathrm{SSC} / 0.1 \%$ SDS for $15 \mathrm{~min}$, followed by two room temperature washes in $0.1 \times \mathrm{SSC} /$ $0.1 \% \mathrm{SDS}$ for $15 \mathrm{~min}$, and a final $65^{\circ} \mathrm{C}$ wash in $0.1 \times \mathrm{SSC} / 0.1 \%$ SDS for $2 \mathrm{~min}$.

DNA constructs and sequencing. DNA fragments from genomic cosmids were subcloned into pBluescript II SK ${ }^{-}$(Stratagene, La Jolla, CA) as described (17). Sequencing of double-stranded DNA templates was carried out using the dideoxy chain termination method (18) using the Sequenase 2.0 kit (U.S. Biochem. Corp., Cleveland, OH). Sequence management was done using the Intelligenetics program (Intelligenetics, Inc., Mountain View, CA) suite running on a Sun workstation (Sun Microsystems, Inc., Mountain View, CA).

$P C R$ amplification. Cloned DNA inserts and total human DNA samples were amplified by PCR as described (19). Genomic DNA $(100 \mathrm{ng})$ or cosmid DNA (5 ng) was amplified in a $25-\mu$ l reaction containing $20 \mathrm{pmol}$ of each oligonucleotide primer, $200 \mu \mathrm{M}$ each of dCTP, dGTP, dTTP, and dATP, $1.5 \mathrm{mM} \mathrm{MgCl}_{2}, 10 \mathrm{mM}$ Tris ( $\mathrm{pH} 8.3$ at $20^{\circ} \mathrm{C}$ ), $50 \mathrm{mM} \mathrm{KCl}$, and $2 \mathrm{U}$ of Taq polymerase (Boehringer Mannheim Biochemicals). Amplification conditions were $94^{\circ} \mathrm{C}$ for $7 \mathrm{~min}$ followed by 25 cycles of $94^{\circ} \mathrm{C}$ for $1 \mathrm{~min}, 62^{\circ} \mathrm{C}$ for $1 \mathrm{~min}$, and $72^{\circ} \mathrm{C}$ for 1 min. Primers for amplification across the deletion were $403 \mathrm{fwd}, 5^{\prime}$ CCTACCTTTCCTGCTGCAAT-3'; and 403rev, 5'-AAAAAGAGGCCGGGTATGGT-3'.

\section{Results}

SVAS kindred 2049. K2049 is a two-generation family from Nevada with two affected individuals (Fig. 1). This family was too small for segregation analysis, but autosomal dominant

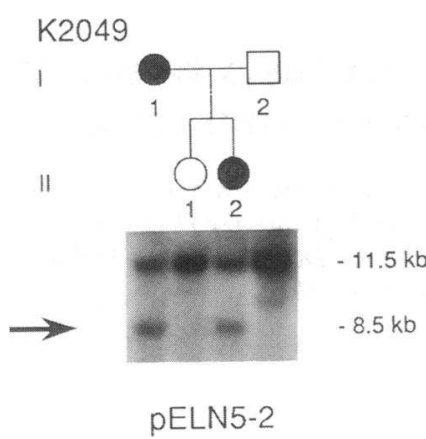

Figure 1. Pedigree structure for K2049 and Southern blot showing EcoRV anomaly. Individuals with the characteristic features of SVAS are indicated by filled circles (females) or squares (males). Open circles or squares represent unaffected individuals. Hybridization of elastin genomic probe pELN5-2 to EcoRV digests of DNA from this kindred revealed an $8.5-\mathrm{kb}$ aberrant fragment in DNA from affected members. The $11.5-\mathrm{kb}$ fragment was observed in affected and unaffected members of this kindred.

transmission of SVAS is apparent. The proband (II-2) had right ventricular hypertrophy, supravalvular pulmonic stenosis (SVPS), bilateral narrowing of the pulmonary arteries (left more severe than right), and a diffusely narrowed ascending aorta with a discrete supravalvular narrowing diagnosed by cardiac catheterization at $6 \mathrm{wk}$ of age. This patient also had intermittent acrocyanosis and hypertension. The most recent echocardiogram at 16 mo of age showed mild SVAS, moderate right ventricular hypertrophy, narrowed pulmonary arteries, and improvement of SVPS. Peak pulmonary artery velocity measured $3 \mathrm{~m} / \mathrm{s}$ (normal, $0.7-1.1 \mathrm{~m} / \mathrm{s}$ ) and peak aortic velocity was 3 $\mathrm{m} / \mathrm{s}$ ( normal, $1.2-1.8 \mathrm{~m} / \mathrm{s}$ ) with aortic turbulence noted on Doppler studies. The proband also had some features common to WS, including dolichocephaly, bitemporal narrowness, outer canthal distance $<2$ SD below the mean, periorbital fullness, broad mouth, full cheeks, a hoarse voice, and hypersensitivity to loud noises. The diagnosis of WS was not made in this child because the patient did not show other features of the disorder; she had normal serum calcium levels, a normal urine calcium/creatinine ratio, normal psychomotor development, and normal growth parameters (length, weight, and head circumference all between the 25 th and 50 th percentile). High resolution chromosome studies and renal ultrasound were normal. This child was treated with phenobarbital for seizures. The mother (I-1) of the proband had a history of seizures in adolescence. Since childhood she has had a grade III/VI early systolic murmur heard best at the suprasternal notch and radiating to the left carotid. Doppler echocardiography studies were not completed in this individual. Other family members were unavailable for this study, but medical records indicated that at least two other family members were affected by SVAS. The mother's brother had narrowing of the entire pulmonary arterial tree diagnosed by cardiac catheterization and was treated for seizures. A maternal first cousin had severe bilateral peripheral pulmonic stenosis, right ventricular hypertrophy, and mild SVAS diagnosed by echocardiogram.

Identification of PFGE and Southern anomalies in DNA from SVAS patients. To test the hypothesis that mutations in the elastin gene cause SVAS, we used elastin genomic probes (Fig. 2) to screen for anomalous restriction fragments in DNA from members of SVAS K2049. Using Southern analyses, elastin genomic probe pELN5-2 identified anomalous EcoRV restriction fragments of $8.5 \mathrm{~kb}$ in affected family members but not in unaffected members (Fig. 1). The 8.5-kb anomalous EcoRV fragment was not observed in DNA samples of $>100$ unrelated control individuals, indicating that it is not a common polymorphism (data not shown). This finding is consis- 


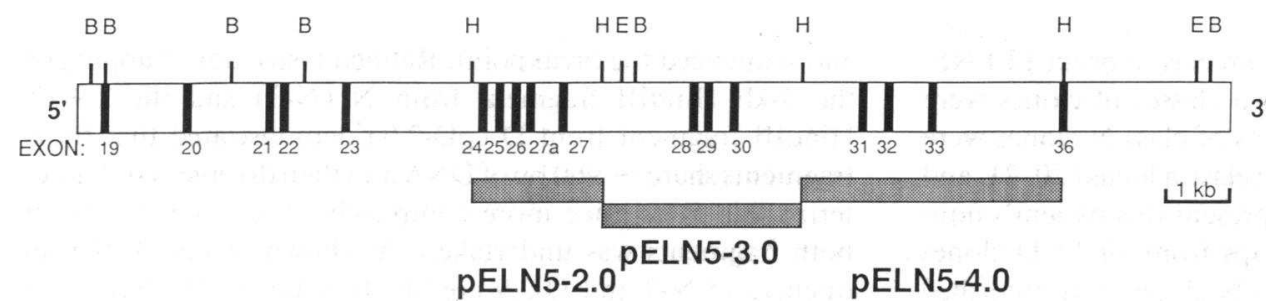

Figure 2. Restriction map of the $3^{\prime}$ end of the elastin gene showing the intron and exon structure and the location of probes used to define the SVAS-associated mutation. Restriction sites are indicated $(B$, BamHI; $H$, HindIII; $E$, EcoRI).

tent with a rare EcoRV polymorphism, an insertion containing a new EcoRV site, a translocation, a deletion, or an inversion.

To confirm these findings and resolve the mechanism of this anomaly, we repeated these experiments using pulsed-field gel electrophoresis (PFGE). High molecular weight DNA extracted from lymphoblastoid cells of affected and unaffected family members was incubated with the restriction enzyme NotI. The resultant restriction fragments were separated by PFGE and transferred to nylon membranes. Hybridization with elastin genomic clones pELN5-2 and pELN5-3 revealed NotI fragments of 600 and $700 \mathrm{~kb}$ in affected members of K2049 (Fig. 3 A). By contrast, in unaffected members of this family, only the 700-kb NotI fragment was observed. These anomalous restriction fragments were not identified in DNA from controls, so they are unlikely to be neutral polymorphisms or the result of variable methylation. These data suggest that an SVAS-associated mutation is located near the elastin locus. Possible mutations that could explain these data include a rare NotI site polymorphism cosegregating with the disease, a deletion, an insertion that creates a NotI site, an inversion, or a translocation.

The SVAS-associated mutation disrupts the elastin gene. To define the location and character of the SVAS-associated mutation, we used genomic subclones that span the 3 ' half of the elastin gene (Fig. 2) to probe NotI filters of DNA from affected and unaffected family members. In affected members of this family, the more 5' elastin probes (pELN5-2, pELN5-3) detected the 600 -kb anomalous NotI fragment (Fig. $3 \mathrm{~A}$ ) and the $700-\mathrm{kb}$ fragment that was also detected in unaffected family members and control subjects. By contrast, the $3^{\prime}$ elastin probe pELN5-4 identified only the 700-kb NotI fragment in both affected and unaffected family members (Fig. $3 A$, and data not shown). These data suggest that the SVAS-associated mutation is a deletion affecting sequences in the $3^{\prime}$ region of the elastin gene with a breakpoint within sequences covered by pELN5-3. A translocation is unlikely because pELN5-4 would be expected to identify a different anomalous fragment. These data are not consistent with a novel NotI polymorphism, an insertion, or an inversion because pELN5-4 would also detect the 600-kb anomalous NotI fragment.

To confirm these findings and further define the mutation, we repeated these experiments using Southern analyses. An 8.5-kb EcoRV anomalous fragment detected with elastin probes pELN5-2 and pELN5-3 was not seen with elastin probes pELN5-4 (Fig. $3 \mathrm{~B}$ ). These data are consistent with a deletion with a breakpoint in sequences represented by pELN5-3. Additional data substantiated this hypothesis. Elastin probe pELN5-3 detected anomalous restriction fragments in DNA samples from affected individuals with BclI, HindIII, SacI, and PvuII (data not shown). pELN5-2 detected identical anomalous BclI, SacI, and PvuII restriction fragments, but no anomalous fragments were detected in HindIII digests with pELN5-2 (these probes were generated from HindIII digests of a large elastin clone as shown in Fig. 2). Of the elastin probes tested, only pELN5-3 detected an anomalous fragment in HindIII digests of affected family members (data not shown); pELN5-2 and pELN5-4 all identified HindIII fragments of the predicted size in affected and unaffected members of this kindred. No anomalous restriction fragments were defined with any enzyme tested by the 3 ' elastin probe pELN5-4. These data strongly suggest that the SVAS-associated mutation is a deletion beginning with sequences represented by elastin probe pELN5-3 and extending in a 3 ' direction.

To confirm these findings and refine the location of the mutation, we cloned the elastin gene from an affected member of K2049. A cosmid library was generated from partially cut, size-selected DNA obtained from affected individual II-2 (Fig.

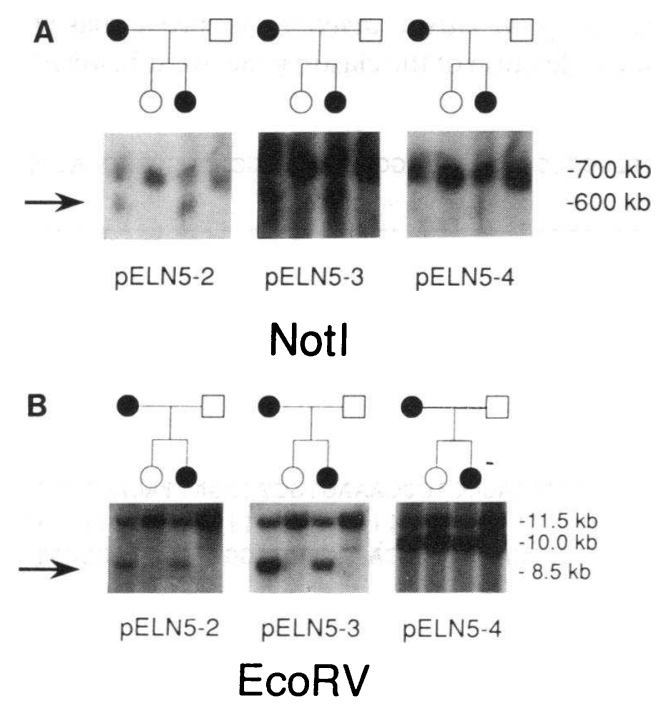

Figure 3. Anomalous restriction fragments on pulsed field and Southern filters defined by elastin probes in DNA isolated from SVAS patients. $(A)$ Hybridization of the more 5 ' elastin genomic probes pELN5-2 and pELN5-3 to NotI digests of DNA from affected members of K2049 revealed aberrant fragments of $600 \mathrm{~kb}$. By contrast, the 3' elastin genomic probe pELN5-4 failed to show the aberrant $600-\mathrm{kb}$ fragment. All three elastin probes detected the $700-\mathrm{kb}$ fragment that was seen in affected and unaffected members of this kindred and represents the normal allele. These data show that an SVAS-associated mutation disrupts the elastin gene and suggest that the mutation is a deletion or an insertion with a breakpoint within the region covered by pELN5-3. (B) Elastin probes pELN 5-2 and pELN5-3 detect an anomalous fragment of $8.5 \mathrm{~kb}$ with EcoRV digests in DNA from affected members of K2049. Elastin probe pELN5-4 failed to detect this anomalous fragment. The 11.5- and 10-kb fragments were seen in affected and unaffected members of this and other kindreds. The 8.5-kb anomalous fragment was not seen in 100 unrelated control subjects. Taken together with PFGE analyses, these data suggest that the SVAS-associated mutation is a deletion of the $3^{\prime}$ end of the elastin gene. 
1). When an 800-bp PstI fragment from elastin probe pELN53 was used to screen this library, two classes of clones were identified, $\mathrm{N}$ and $\mathrm{D}$. Restriction maps of class $\mathrm{N}$ clones were consistent with published maps of the elastin locus (20,21, and data not shown ) and presumably represent this patient's nondeleted elastin allele. Restriction maps from all $14 \mathrm{D}$ clones showed some shared fragments with $\mathrm{N}$ clones and published maps, but the $\mathrm{D}$ map diverged at one end, resulting in a novel 2.9-kb HindIII restriction fragment that hybridized with pELN5-3 (data not shown). One explanation for these mapping data is that $\mathrm{D}$ represents the deletion allele.

To test the hypothesis that $\mathrm{D}$ clones represent the deletion allele, HindIII fragments from both $\mathrm{N}$ and $\mathrm{D}$ were subcloned and sequenced. The restriction fragment pattern was similar in all D clones, and when pELN5-3 was used to probe a Southern blot of these fragments, all D clones showed a 2.9-kb anomalous fragment. All $\mathrm{N}$ clones showed the expected 3.0-kb fragment (data not shown). Sequence analysis of the $3.0-\mathrm{kb}$ HindIII fragments from $\mathrm{N}$ showed that this clone contained elastin exons 28-30 (data not shown). By contrast, PCR and sequence analysis failed to detect elastin exons in the 2.9-kb HindIII subclone of D (data not shown). These data suggest that $\mathrm{D}$ clones represent the germline allele derived from a deletion of the $3^{\prime}$ end of one elastin allele, a mutation that disrupted exons 28-36.

Sequence analysis of the elastin deletion. To prove that D represents a germline deletion of the elastin gene, we subcloned and sequenced the breakpoint. Refined restriction mapping of the 3-kb HindIII fragment from $\mathrm{N}(\mathrm{N}-3)$ and the $2.9-\mathrm{kb}$ HindIII fragment from $\mathrm{D}$ (pD-2.9) demonstrated that these fragments share $\sim 960$ bp of DNA and then diverge. To characterize this divergence more completely, direct sequencing of both fragments was undertaken. As shown in Fig. 4, the sequences of N-3 and D-2.9 are identical for $\sim 231$ bases and then diverge. The point of divergence presumably represents the deletion breakpoint and lies in intronic sequence $\sim 366$ bases proximal of exon 28 . The DNA sequences 3 ' of the breakpoint (Fig. 4) showed no homology to any known genes when entered into GenBank.

To confirm that the $14 \mathrm{D}$ clones represent the deletion allele and did not result from cloning artifacts, a 4.5-kb HindIII fragment representing D sequence $3^{\prime}$ of the breakpoint was used to probe pulsed-field filters. This probe detected the 700$\mathrm{kb}$ normal NotI fragment and the 600 -kb aberrant fragment in genomic DNA of a member of K2049 who carried the SVASassociated mutation (Fig. 5). By contrast, DNA from unaffected family members and controls gave only the expected $700-\mathrm{kb}$ band. If $\mathrm{D}$ clones resulted from cloning artifacts, this probe would detect novel abberrant fragments in DNA samples from both affected and unaffected individuals. Since probes from either side of the breakpoint detect identical NotI fragments, the SVAS-associated deletion must be relatively small ( $100 \mathrm{~kb})$. Southern blots of DNA from K2049 were also probed with $\mathrm{D}$ and other breakpoint clones. The expected

N TTTGACAGAGTCTTGCTCTGTCGCCCAGgCTGGAATGCAGTGGTACGATCTGGCTCCCTGCAGCCTCCATCTCCCGGGTTCAAGTGATTCTCCTGCCTCAGCCTTCC D

N AAGTAGCTGGGATTACAGGCGCCCGCCACCACGCCTGGCTAATTTTTGTATTTTTCGTAGAAACAGGGTTTCACCGTGTTGGCCAGGCTGGTCTCAAACTCCTGACC D

N TCAGgTGATCCACTAGCCTCAGCCTCCCAAAGTGCTGGGATTACAGGTGTGAGCCACGCACCCGgCTTACAAAAGAACTTTTAAGgCCAGGCACAGTGGTTCACACT

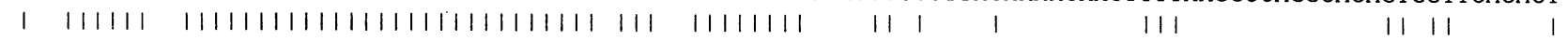
D - - AGATATCCACCCGCCTCAGCCTCCCAAAGTGCTGGgATTATAGgCATGAGCCACCATACCCGgCCTCTTTTTTTAATTTTTATGGATATGTGGTAGTGATATGT

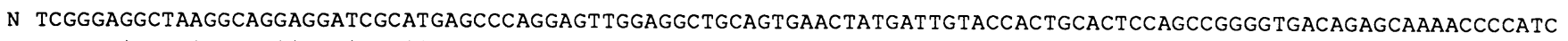

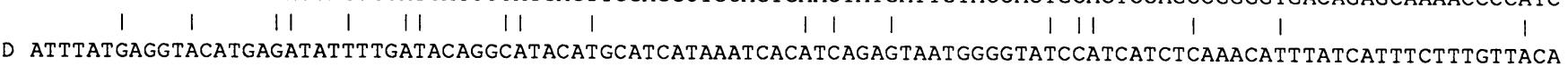

N TCAAAATGAAACAAAATATGGACTGGACTTCCTGTCCACTGCTCCTCCACAGTGTCACATGGCCCCTGCCACCTGTCTGCTTGCCTTGTGTCCCTGGGGCAGGGAGA

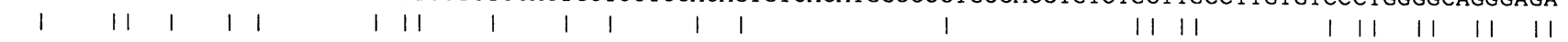

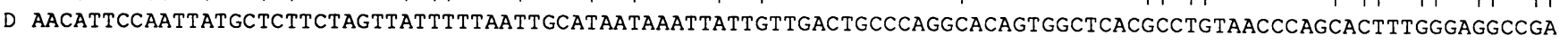

EXON 28

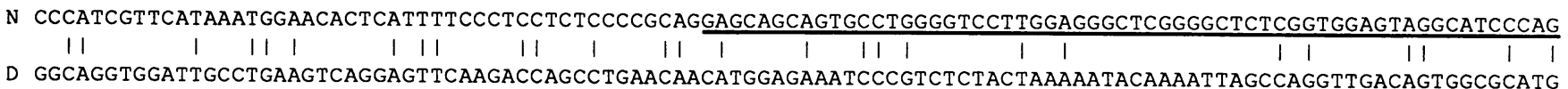

D GgCAgGTGGATTGCCTGAAGTCAGgAGTTCAAGACCAGCCTGAACAACATGGAGAAATCCCGTCTCTACTAAAAATACAAAATTAGCCAGGTTGACAGTGGCGCATG

N GCGGTGTGGTGGGTGA
D CTGTATCCAGCTACTT

Figure 4. Nucleotide sequence of the deletion breakpoint. Nucleotide sequence of the N (nondeletion) and D (deletion) alleles showing complete identity until the site of deletion indicated by an arrow. The deletion disrupts intron 27 and subsequent sequences. Nucleotide identity is indicated as a broken line up to the breakpoint and by a dash thereafter. Note the high degree of DNA sequence identity at the breakpoint. This sequence identify contains Alu and Alu-like repetitive sequences. These sequence data have been submitted to GenBank under accession number L23859. 


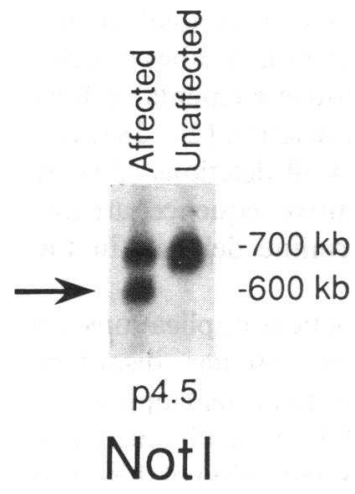

Figure 5. PFGE analyses showing that $D$ represents a germline deletion in the elastin gene. A 4.5-kb HindIII subclone of D located 3' of the breakpoint ( $\mathrm{p} 4.5$ ) was used to probe a NotI filter. $\mathrm{p} 4.5$ detected NotI fragments of 700 and $600 \mathrm{~kb}$ in an affected family member of K2049, but only the 700$\mathrm{kb}$ fragment in unaffected members. These data show that $D$ represents the deletion allele and that the deletion spans $\sim 100 \mathrm{~kb}$.

anomalous fragments were seen with BclI-, EcoRV-, PvuII-, and SacI-digested DNA from affected individuals when probed with clones 3 ' of the breakpoint; no anomalous fragments were observed when these clones were used to analyze DNA from unaffected family members and controls (data not shown). To further confirm that the $14 \mathrm{D}$ clones represent deletion alleles and are not cloning artifacts, oligonucleotide primer pairs (403fwd and 403rev) were generated on either side of the deletion for PCR analysis of the breakpoint (Fig. $6 \mathrm{~A}$ ). These primers produced a product of the predicted size ( $403 \mathrm{bp})$ in

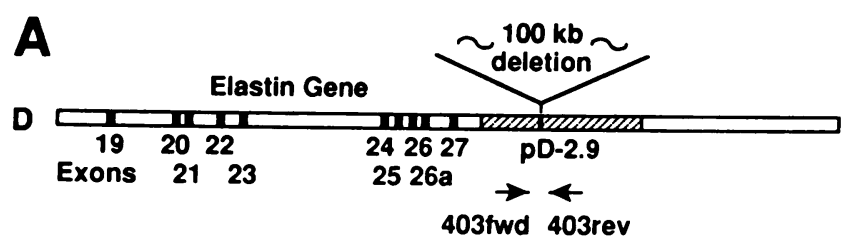

B

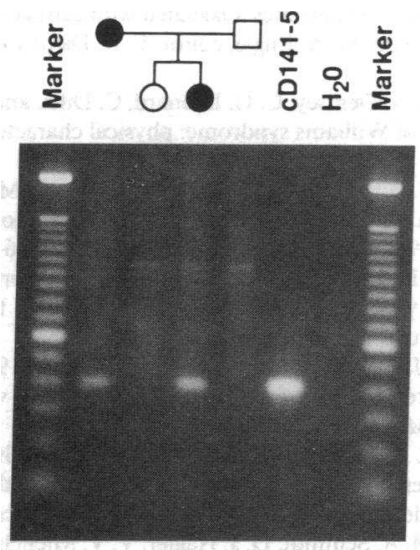

Primers 403fwd and 403rev

Figure 6. PCR analyses showing that $\mathrm{D}$ represents a deletion allele. $(A)$ Map of the $\mathrm{D}$ clone showing the deletion breakpoint, the 2.9-kb HindIII fragment from D (pD-2.9), and the location of the oligonucleotide primers ( $403 \mathrm{fwd}$ and $403 \mathrm{rev}$ ). ( $B$ ) Oligonucleotide primers directed across the deletion breakpoint (403fwd and 403rev) yield a PCR product of the predicted size ( $403 \mathrm{bp}$ ) in affected members of K2049 and in a D clone (cD141-5), but not in unaffected family members. These data show that $\mathrm{D}$ represents the deletion allele, and the deletion disrupts the elastin gene.
PCRs performed on template DNA from affected members of K2049 and a D clone (cD141-5; Fig. 6 B). By contrast, these same primers failed to generate a product on unaffected family members. These data indicate that sequences derived from $D$ clones represent the deletion allele and demonstrate that this $100-\mathrm{kb}$ deletion disrupts the $3^{\prime}$ end of elastin allele.

\section{Discussion}

Our data show that a 100-kb deletion associated with SVAS in one family disrupts the $3^{\prime}$ end of the elastin gene. In previous studies we demonstrated complete linkage between SVAS and DNA markers at the elastin locus in two families (5). We then showed that a balanced translocation that cosegregated with the disease in a third family disrupted the elastin gene $(6,7)$. Linkage between SVAS and markers on chromosome $7 \mathrm{q}$ was recently observed in a fourth family (22). This study demonstrates a second SVAS-associated elastin mutation, strongly suggesting that mutations in the elastin gene cause this disorder.

Several additional lines of evidence support a role for elastin in SVAS. First, we recently demonstrated familial and de novo deletions of the entire elastin locus in patients with WS, a developmental disorder that includes SVAS (8). Second, the physiology of the vascular system, particularly the aorta, suggests that abnormalities in elastin could cause SVAS. Hemodynamic strain on the vascular system is ameliorated by elastic fibers in the media; these fibers absorb energy during cardiac systole and release energy during diastole (23). Reduced vascular elasticity would have a deleterious effect on vascular homeostasis, and since hemodynamic stress is greatest in the ascending aorta, this structure would be most severely affected. Third, the pathology of SVAS is consistent with a primary defect of elastin. In SVAS, elastic tissue is disrupted, disorganized, and reduced in content (24). Increased collagen and smooth muscle cell hypertrophy, also observed in SVAS, presumably represent secondary phenomena. Finally, reports of transient SVAS in patients with the Marfan syndrome support a role for elastic fibers in this disorder. Fibrillin, the protein implicated in Marfan syndrome, is a major component of elastic fibers and interacts with elastin during fiber development (25).

The precise mechanism of SVAS is not known, but it is interesting to note that both SVAS-associated mutations described thus far disrupt the $3^{\prime}$ end of the elastin gene. The elastin gene consists of alternating hydrophobic and cross-linking domains. The hydrophobic domains are thought to represent a coiled coil and confer the protein's resiliency while the crosslinking residues are critical for intra- and intermolecular interactions. We do not yet know if the mutant elastin gene described here is expressed, but if it is, a truncated protein lacking desmosine cross-link sites and two highly conserved cysteine residues would result (Fig. 7). This protein would also lack a microfibril-associated glycoprotein (MAGP) binding site, which exists in the carboxy terminus of elastin (R. Mecham, personal communication). An elastin protein lacking exons 28-36 might have a dominant-negative effect on formation of complex elastic fibers seen in the vascular system, but have relatively little effect on elastic tissue in other organs, like the skin and lungs. Alternatively, disruption of the 3 ' end of the elastin gene might have a quantitative effect on elastin mRNA or protein. Our data, showing that hemizyogosity at the elastin locus can cause SVAS in WS, suggest that a quantitative defect 


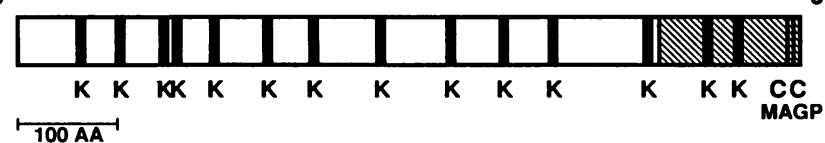

Figure 7. Schematic representation of elastin protein showing deleted region. The hatched area indicates domains deleted in affected members of K2049. Elastin contains multiple lysyl oxidase crosslinking domains $(K)$; two cross-linking domains are disrupted by the deletion. This region also contains two highly conserved cysteines residues near the carboxy terminus and a binding site for MAGP.

in elastin during development can cause this vascular disease. However, patients with WS have additional connective tissue abnormalities (skin, skeletal, joint, subcutaneous tissue) not commonly reported in SVAS patients. Continued mutational analysis of patients with SVAS and WS and analysis of elastin expression in tissue obtained from patients will help distinguish between these mechanisms.

We have identified two classes of elastin gene mutations, mutations involving part of the gene (the $100-\mathrm{kb}$ deletion described here and a translocation ) and large deletions involving the entire gene and adjacent sequences (8). The latter class of mutation is associated with WS, a complex developmental disorder including vascular disease (SVAS), connective tissue abnormalities (dysmorphic facial features, joint contractures, hernias), infantile hypercalcemia, mental retardation, and specific neurobehavioral features (2-4). Although the size of these WS-associated deletions is not yet known, they span at least $250 \mathrm{~kb}$ (our unpublished observations) and presumably disrupt adjacent, as yet undefined, genes. By contrast, the deletion described here is smaller $(100 \mathrm{~kb})$ and disrupts only the $3^{\prime}$ end of the elastin gene. This mutation, and the previously described translocation involving the same elastin domains, is primarily associated with SVAS. Although isolated members of SVAS kindreds (for example, individual II-2 in the family described here) have additional connective tissue abnormalities (mild dysmorphic facial features, hoarse voice), none of the other features of WS (hypercalcemia, mental retardation, neurobehavioral features) have been observed in these patients. The elastin gene is expressed during development of the central nervous system (26), but the lack of cognitive and behavioral disorders in patients with autosomal dominant SVAS makes it unlikely that elastin mutations alone account for the WS phenotype. Instead, we hypothesize that hemizygosity at the elastin locus accounts for many of the connective tissue abnormalities seen in WS (including vascular disease), but that disruption of adjacent genes is the mechanism of additional WS features. Since no genotypic differences between members of autosomal dominant SVAS families have been identified, intrafamilial variation in the severity of vascular disease and the presence or absence of dysmorphic features probably results from other genetic and environmental factors. Further, careful phenotyping of SVAS and WS subjects, identification of genes adjacent to the elastin locus, and a detailed genotypic analysis of these patients may help elucidate the mechanisms underlying these disorders.

Although a number of DNA deletions have been sequenced, the precise mechanism of deletion is not known. In this study, sequence analysis of the breakpoint region identified a 300-bp Alu repeat within the elastin intron 27 . Similar repetitive sequences were identified $3^{\prime}$ of the breakpoint (Fig. 4), suggesting that nonhomologous pairing and an unequal recombination event might account for the deletion. Studies of deletions have led to suggestions that repetitive elements such as Alu are involved in the mechanism of deletion $(27,28)$, but repetitive elements are not involved in all deletions (29). It appears likely, however, that these repetitive sequences are important in the mechanism of the germline deletion in the kindred studied here.

Our work on SVAS may have practical implications for treatment of this and other similar vascular disorders. Currently, vascular surgery is the only treatment option for SVAS. If vascular obstruction in SVAS is caused by increased hemodynamic stress to inelastic arteries, reduction of this stress may reduce progression of the disease. Pharmacological agents, like $\beta$-adrenergic blockers, are already used for the successful management of vascular disease in Marfan syndrome (30). These agents, which reduce heart rate and blood pressure, may also prove effective in SVAS.

\section{Acknowledgments}

We thank M. Curran, M. Leppert, and R. White for their help and advice. We thank $S$. Nelson for coordinating the field trips and M. Woodward for cell culture. We thank W. N. Evans for referral and cardiac evaluation of the propositus.

This work was supported by National Institutes of Health grant RO1 HL-4807, Public Health Services research grant MO1 RR-00064 from the National Center for Research Resources, a March of Dimes grant, an American Heart Association grant, and the Technology Access Section of the Utah Genome Center.

\section{References}

1. Eisenberg, R., D. Young, B. Jacobson, and A. Voito. 1964. Familial supravalvular aortic stenosis. Am. J. Dis. Child. 108:341-347.

2. Grimm, T., and H. Wesselhoeft. 1980. Zur Genetik des Williams-BeurenSyndroms und des isolierten from der Supravalvularen Aorten-Stenose Untersuchungen von 128 Familien. Z. Kardiol. 69:168-172.

3. Noonan, J. A. 1981. Syndromes associated with cardiac defects. In Pediatric Cardiovascular Disease. M. A. Engle, editor. F. A. Davis Company, Philadelphia. 97-116.

4. Morris, C. A., S. A. Demsey, C. O. Leonard, C. Dilts, and B. L. Blackburn, 1988. Natural history of Williams syndrome: physical characteristics. J. Pediatr. 113:318-326.

5. Ewart, A. K., C. A. Morris, G. J. Ensing, J. Loker, C. Moore, M. Leppert, and M. Keating. A human vascular disorder, supravalvular aortic stenosis, maps to chromosome 7. 1993. Proc. Natl. Acad. Sci. USA. 90:3226-3230.

6. Curran, M. E., D. L. Atkinson, A. K. Ewart, C. A. Morris, M. F. Leppert, and $M$. T. Keating. 1993. The elastin gene is disrupted by a translocation associated with supravalvular aortic stenosis. Cell. 73:159-168.

7. Morris, C. A., J. Loker, G. Ensing, and A. D. Stock. 1993. Supravalvular aortic stenosis cosegregates with familial 6;7 translocation which disrupts the elastin gene. Am. J. Med. Genet. 46:737-744.

8. Ewart, A. K., C. A. Morris, D. A. Atkinson, W. Jin, K. Sternes, P. Spallone, A. D. Stock, M. Leppert, and M. T. Keating. Hemizygosity at the elastin locus in a developmental disorder, Williams syndrome. Nature Genetics. 5:11-16.

9. Ensing, G. J., M. A. Schmidt, D. J. Hagler, V. V. Michels, G. A. Carter, and R. H. Feldt. 1989. Spectrum of findings in a family with nonsyndromic autosomal dominant supravalvular aortic stenosis: a doppler echocardiographic study. J. Am. Coll. Cardiol. 13:413-419.

10. Bell, G., J. H. Karem, and W. J. Rutter. 1981. Polymorphic DNA region adjacent to the $5^{\prime}$ end of the human insulin gene. Proc. Natl. Acad. Sci. USA. 78:5759-5763.

11. Kunkel, L. M., K. D. Smith, S. H. Boyer, S. S. Borgaonkar, S. S. Wachtel, O. J. Miller, and W. R. Breg. 1977. Analysis of human Y-chromosome-specific reiterated DNA in chromosome variants. Proc. Natl. Acad. Sci. USA. 74:12451249.

12. Southern, E. M. 1975. Detection of specific sequences among DNA fragments separated by gel electrophoresis. J. Mol. Biol. 98:503-517.

13. Feinburg, A. P., and B. Vogelstein. 1984. A technique for radiolabeling 
DNA restriction endonuclease fragments to high specific activity. Anal. Biochem 137:266-267.

14. Schwartz, D. C., and C. R. Cantor. 1984. Separation of yeast chromosome-sized DNAs by pulsed field gel electrophoresis. Cell. 37:67-75.

15. Wahl, G. M., K. A. Lewis, J. C. Ruiz, B. Rothenberg, J. Zhao, and G. A. Evans. 1987. Cosmid vectors for rapid genomic walking, restriction mapping, and gene transfer. Proc. Natl. Acad. Sci. USA. 84:2160-2164.

16. Benton, W. D., and R. W. Davis. 1977. Screening I-gt recombinant clones by hybridization to single plaques in situ. Science (Wash. DC)., 196:180-182.

17. Maniatis, T., E. F. Fritsch, and J. Sambrook. 1982. Molecular Cloning: A Laboratory Manual. Vol. 1. Cold Spring Harbor Laboratory Press, Cold Spring Harbor, NY. 416 pp.

18. Sanger, F., S. Nicklen, and A. R. Coulson. 1977. DNA sequencing with chain-terminating inhibitors. Proc. Natl. Acad. Sci. USA. 74:5463-5467.

19. Saiki, R., D. Gelfand, S. Stoffel, S. Scharf, R. Higuchi, G. Horn, K. Mullins, and H. Erlich. 1988. Primer-directed enzymatic amplification of DNA with a thermostable DNA polymerase. Science (Wash. DC). 239:487-491.

20. Bashir, M., Z. Indik, H. Yeh, N. Ornstein-Goldstein, J. Rosenbloom, W Abrams, M. Fazio, J. Uitto, and J. Rosenbloom. 1991. Characterization of the complete human elastin gene. J. Biol. Chem. 264:8887-8891.

21. Indik, K., H. Yeh, N. Ornstein-Goldstein, P. Sheppard, N. Anderson, J. Rosenbloom, L. Peltonen, and J. Rosenbloom. 1987. Alternative splicing of human elastin mRNA indicated by sequence analysis of cloned genomic and complementary DNA. Proc. Natl. Acad. Sci. USA. 84:5680-5684.

22. Olson, T. M., V. V. Michels, N. M. Lindor, G. M. Pastores, J. L. Wever D. J. Schaid, D. J. Driscoll, R. H. Feldt, and S. N. Thibodeau. 1993. Autosomal dominant supravalvular aortic stenosis: localization to chromosome 7. Human Molecular Genetics. 2:869-873.

23. Uitto, J., A. M. Christiano, V-M. Kahari, M. M. Bashir, and J. Rosenbloom, J. 1991. Molecular biology and pathology of human elastin. Biochem. Soc. Trans. 19:824-229.

24. O'Connor, W., J. Davis, R. Geissler, C. Cottrill, J. Noonan, and E. Todd. 1985. Supravalvular aortic stenosis: clinical and pathologic observations in six patients. Arch. Pathol. Lab. Med. 109:179-185.

25. Sakai, L., D. Keene, and E. Engvall. 1986. Fibrillin, a new 350-kD glycoprotein, is a component of extracellular microfibrils. J. Cell Biol. 103:2499-2509.

26. Baumbach, G., J. Siems, F. Faraci, and D. Heistad. 1989. Mechanics and composition of arterioles in brain stem and cerebrum. Am. J. Physiol. 256:H493501.

27. Botto, M., K. Fong, A. So., R. Barlow, R. Routier, B. Morley, and M. Walport. 1992. Homozygous hereditary C3 deficiency due to a partial gene deletion. Proc. Natl. Acad. Sci. USA. 89:4957-4961.

28. Lacerra, G., G. Fioretti, M. De Angioletti, L. Pagano, E. Guarino, C. de Bonier, A. Viola, G. Maglione, A. Scarallo, L. De Rosa, and D. Carestia. 1991. $(\alpha) \alpha^{5.3}$ : a novel $\alpha^{+}$-thalassemia deletion with the breakpoints in the $\alpha 2$-globin gene and in close proximity to an alu family repeat between the $\psi \alpha 2$ - and $\psi \alpha 1$ globin genes. Blood. 78:2740-2746.

29. Morris, T., and J. Thacker. 1993. Formation of large deletions by illegitimate recombination in the HPRT gene of primary human fibroblasts. Proc. Natl. Acad. Sci. USA. 90:1392-1396.

30. Taherinia, C. 1993. Cardiovascular anomalies in Marfan's syndrome: the role of echocardiography and $\beta$-blockers. South. Med. J. 86:305-310. 